This is a postprint version of the following published document:

Dios, M.; González, Z.; Alvaredo, P.; Bermejo, R.; Gordo, E.; Ferrari, B. Novel colloidal approach for the microstructural improvement in $\mathrm{Ti}(\mathrm{C}, \mathrm{N}) /$ FeNi cermets. Journal of Alloys and Compounds, 742, pp. 327-338, 15 November 2017

DOI: https://doi.org/10.1016/i.jallcom.2017.07.034

(C) 2017 Published by Elsevier B.V.

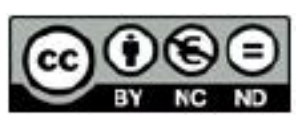

This work is licensed under a Creative Commons Attribution-NonCommercialNoDerivatives 4.0 International License. 


\title{
Novel colloidal approach for the microstructural improvement in $\mathrm{Ti}(\mathrm{C}, \mathrm{N}) / \mathrm{FeNi}$ cermets
}

\author{
M. Dios ${ }^{\text {a, }}{ }^{\text {, }}$, Z. Gonzalez ${ }^{\text {b }}$, P. Alvaredo ${ }^{a}$, R. Bermejo ${ }^{c}$, E. Gordo ${ }^{\text {a }}$, B. Ferrari ${ }^{\text {b }}$ \\ a Department of Materials Science and Engineering and Chemical Engineering, IAAB University Carlos III of Madrid, Avda. Universidad 30, 28911, Leganes, \\ Madrid, Spain \\ ${ }^{\mathrm{b}}$ Institute of Ceramic and Glass, CSIC, C/Kelsen 5, 28049, Madrid, Spain \\ c Institut für Struktur- und Funktionskeramik, Montanuniversitat Leoben, Franz Josef Strasse 18, 8700, Leoben, Austria
}

In this work, the combination of colloidal and powder metallurgy techniques was proposed as an alternative route to produce $\mathrm{Ti}(\mathrm{C}, \mathrm{N})$ based cermets with a $1520 \mathrm{vol} \%$ of Fe/Ni alloy (85/15 wt\%) as metal matrix. The novelty of this processing route is based in the mixture of fine powders ( $13 \mu \mathrm{m})$ in sus pension which promotes the uniformity of the phase distribution and consequently its reactivity, leading to $99.9 \%$ dense cermets with 1300 Vickers Hardness (HV30). The preparation of colloidal and chemically stable slurries of non oxide and metal powders in aqueous media is a key step of the process. Highly concentrated aqueous slurries of $\mathrm{Ti}(\mathrm{C}, \mathrm{N}), \mathrm{Fe}, \mathrm{Ni}$ and $\mathrm{C}$ powders were prepared and mixed. Then bulk pieces were shaped by Slip casting (SC), Slip Casting + Cold Isostatic Pressing (SC CIP) and Spray Dry + Uniaxial Pressing of the obtained spherical granules (SDP). The composite formulation and the thermal treatment were optimized to prevent Ni sublimation during sintering as well as to improve liquid phase sintering in terms of wetting and reactivity among well packed particles. The effective dispersion of the slurry and the synergistic effect of combined techniques yielded the preparation of reliable materials by the SDP process with $15 \mathrm{wt} \%$ of FeNi with the addition of $0.5 \mathrm{wt} \%$ of $\mathrm{C}$. The opti mization of the composite formulation and the processing parameters improves both density and hardness of a finer microstructure of the composite after a short sintering treatment $(120 \mathrm{~min})$ at $1450{ }^{\circ} \mathrm{C}$ in vacuum.

\section{Introduction}

Titanium carbonitride $(\mathrm{Ti}(\mathrm{C}, \mathrm{N}))$ based cermets are widely used to prepare advanced ceramic composites applied in metalworking, electrical and electronic, automotive and refractory industries thanks to their excellent and unique combination of physical properties such as high melting point, thermal conductivity, hardness, wear and oxidation resistance and good thermal and chemical stability [1,2]. In the production of cermets, the starting materials are typically $\mathrm{Ti}(\mathrm{C}, \mathrm{N})$ and a metal binder that is usually $\mathrm{Ni}$, $\mathrm{Co}$, or a combination of both. However one of the main trends in the industry of cermets is the substitution of the conventional binders of $\mathrm{Ni}$ and $\mathrm{Co}$ for metals or alloys with less toxicity and lower cost without losing the characteristic properties of cermets. The principal candidate as alternative metallic matrix is $\mathrm{Fe}$, which has been studied as binder of hardmetals [3-5] and $\mathrm{Ti}(\mathrm{C}, \mathrm{N})$ based cermets [6,7]. However, from the processing point of view, the principal drawback in the use of Fe as binder in cermets is associ ated with its poor wettability on $\operatorname{Ti}(\mathrm{C}, \mathrm{N})$ particles during the liquid phase sintering (LPS). Within this process, the liquid binder in filtrates the ceramic skeleton and thus the sintering microstructure is achieved after the ceramic dissolution and further re precipitation. Therefore, wetting and solubility of the phases become key factors to attain homogeneous materials. Since the wetting behavior of metal binders on $\operatorname{Ti}(C, N)$ is, in general, poorer than in WC, carbides of refractory metals such as WC, VC, and $\mathrm{Mo}_{2} \mathrm{C}$ are added [1,3-8]. However, as a result of these additions a typical core rim structure can be formed and a careful selection of the amount of carbides should be done to avoid the harmful effects of brittle phases formed at the rim. Particularly, the effect of carbide additions in the wetting behavior of Fe has not been widely studied, although some works describe microstructural improvements (see 
for instance $[7,9])$. In another work, instead of adding secondary carbides, the addition of $\mathrm{Ni}$ does improve notably the wetting and solubility behavior of Fe on the $\mathrm{Ti}(\mathrm{C}, \mathrm{N})$ particles [10].

Moreover, the properties of hardmetals and cermets depend largely in the homogeneous distribution of the ceramic and metallic phases [11]. Together with the proper selection of the composition and the interactions between phases, the processing method is a key factor that determines the microstructure and properties [12]. The most common processing route for cermets is the conventional powder metallurgy route, which imply the milling of powders for long times (up to $36 \mathrm{~h}$ in attritor ball mill, 2-7 days in a ball mill) using organic liquid media (ethanol, isopropanol, or others) and a binder or lubricant such as polyethylene glycol (PEG), paraffin wax or others [13]; after milling the powders are dried, and could be granulated for a better pressing behavior. Powders are shaped by uniaxial pressing or cold isostatic pressing followed by sintering at high temperatures, usually in vacuum. In such route, the powder preparation step is critical, as it should provide the appropriate size and dispersion of phases as well as incorporate pressing additives. Other approaches have been explored to obtain high dispersion of phases and to deal with nanosized phases. Park and Kang [14] prepared nano sized $(\mathrm{Ti}, \mathrm{W}) \mathrm{C}-\mathrm{Ni}$ and $(\mathrm{Ti}, \mathrm{W})(\mathrm{CN})-\mathrm{Ni}$ powders $\mathrm{Ti}, \mathrm{W}$ and $\mathrm{Ni}$ oxides by a carbo thermal reduction after high energy milling; the powders were pressed and sintered to obtain an homogeneous and coreless microstructure with good values of toughness. A similar process was used by Brown [15] to obtain $\mathrm{Fe} \mathrm{TiC}$ composites by reduction of ilmenite $\left(\mathrm{FeTiO}_{3}\right)$ with $\mathrm{C}$ to produce powders and a subsequent pressing step and vacuum sintering, claiming to obtain up to $80 \mathrm{wt} \% \mathrm{TiC}$ in iron matrices. Homogeneous Ti based carbonitride solid solutions have been synthesized by a mechanically induced self sustaining reaction (MSR). These powders were successfully employed in the fabrica tion of cermets by uniaxial and cold isostatic pressing [16], hot pressing [17] or spark plasma sintering (SPS) [18], although in all these cases the metallic phase is Co. MSR method is similar to self propagating high temperature synthesis (SHS), that uses the strong exothermic character of the reactant powder mixtures to promote self sustaining reactions. This method is also known as combustion synthesis or reaction synthesis and has been used for the produc tion of a variety of ceramics and ceramic metal composites, including Fe TiC cermets [19,20]. Direct fabrication of bulk hard materials can be realized by combustion synthesis combined with simultaneous densification under a mechanical pressure using hot pressing, SPS or extrusion [21]. A variation of this approach was recently reported to obtain a $\mathrm{Ti}(\mathrm{C}, \mathrm{N})$ based cermet with a $\mathrm{Ni}_{3} \mathrm{Ti}$ intermetallic matrix [22], where the reactant powder mixture is cold pressed, the compact is placed into a reaction chamber, and the combustion synthesis is triggered by an electric current pro ducing the cermet. A similar approach was used to obtain TiC Fe cermets by combination of mechanical activation and SPS from ferrotitanium and carbon black as reactants [23]. These techniques produce in situ carbides into the metal matrix at lower tempera tures than conventional techniques but the control of the process must be very tight to obtain good results. Together with the at tempts to produce highly disperse phases, different shaping and sintering techniques to produce bulk cermets have been explored, particularly those which reduce the processing time in an attempt to maintain fine microstructures avoiding carbides coarsening like hot pressing [24] or SPS [25], or novel and challenging techniques like additive manufacturing [26].

An alternative approach to achieve homogeneous dispersion of the phases and higher control of the microstructures for processing cermets is the use colloidal techniques, which have been success fully implemented for the production of traditional and advanced ceramics at industrial level. The advantages offered by the colloidal route have been demonstrated in the processing of $\mathrm{Ni}$ and $\mathrm{Ni}$ composites [27,28] and Fe based cermets [29] providing controlled microstructures through a very intimate mixture of the ceramic and metal phases, using particles in the micrometric range and avoiding mechanical milling.

The colloidal processing implies the formation of slurries in aqueous media, which is a drawback in the case of both non oxide ceramic and metal particles, due to the elevated reactivity of these materials with the suspension media. From an electrochemical point of view, water is one of the more complex liquid media to work with. It has a very high polar moment which requires tight control of the colloidal and chemical stability of the slurries [30-32] to prevent the particle oxidation, while maintaining the interparticle repulsion networks and thus the slurry stability. However, in addition to the superficial stability of the particles within the dispersion, their flow conditions are another factor of vital importance for the colloidal shaping. The rheological behavior of the high solid content slurries must provide a homogeneous mixture of phases, as well as avoid risks of segregation that may arise during the processing of the bulk pieces.

In this work colloidal and powder metallurgical techniques have been combined in order to produce cermets with different composition (i.e. metal content and $\mathrm{C}$ addition) through different forming methods: (i) Slip casting (SC), (ii) Slip Casting + Cold Isostatic Pressing (SC CIP), and (iii) Spray Dry + Uniaxial Pressing of the spherical granules generated (SDP) [33]. First, a thorough characterization of the starting powders and slurry stability of the mixtures was carried out. Second, a thermal analysis was per formed on the SDP samples to study and understand the sintering behavior of the cermet materials in different atmospheres. Based upon such study, a sintering cycle was designed for the cermets processed through the three different routes. A microstructural characterization followed by hardness measurements were then performed in order to assess the effect of the processing route, the reinforcement/matrix proportion as well as the $\mathrm{C}$ addition on the prospective mechanical behavior of the cermets investigated.

\section{Experimental}

\subsection{Characterization of the starting powders and preparation of the materials}

Titanium carbonitride (Ti(C,N), Ti(C,N) grade C, H.C. Stark, Ger many), iron (Fe, Fe SM, H.C. Stark, Germany) and nickel (Ni, Nickel $210 \mathrm{H}$, INCO, Canada) powders were used as commercial starting materials. Particle size and specific surface area of the powders were determined with a laser analyzer (Mastersizer S, Malvern instruments Ltd., UK) and by one point $\mathrm{N}_{2}$ adsorption (Monosorb Surface Area, Quantachrome Corporation, USA) respectively. Den sity of the as received powders was measured using a Monosorb Multipycnometer (Quantachrome Corporation, USA).

From these powders, high solid content slurries were formu lated using water as dispersion media. The slurries were prepared in deionized water with Tetramethylammonium hydroxide (TMAH) to adjust the $\mathrm{pH}$ up to $10-11$, where surfaces are chemically stable. Then $0.4 \mathrm{wt} \%$ of Polyethylenimine (PEI) was added as dispersant. $\mathrm{Ti}(\mathrm{C}, \mathrm{N}), \mathrm{Fe}$ and Ni slurries were prepared separately and milled in a ball mill for $1 \mathrm{~h}$, using silicon nitride $\left(\mathrm{Si}_{3} \mathrm{~N}_{4}\right)$ and nylon balls for ceramic and metal particles respectively $[29,34]$. In order to eval uate the effect of a small addition of $C$, a graphite suspension of $10 \mathrm{~g} / \mathrm{L}$ was prepared in ethanol using Black Carbon (ISTAM, Ger many) with a density of $2.24 \mathrm{~g} / \mathrm{cm}^{3}$ and a mean particle size of $18 \mu \mathrm{m}$ [35]. After milling, Ti(C,N), Fe/Ni (85/15 wt/wt.) and C sus pensions were mixed to fit four different compositions labeled in Table 1. 
Table 1

Formulation of the suspensions.

\begin{tabular}{|c|c|c|c|c|c|}
\hline \multirow[t]{2}{*}{ Composition } & \multirow[t]{2}{*}{ Ceramic reinforcement $\mathrm{Ti}(\mathrm{C}, \mathrm{N})$ vol\% } & \multirow[t]{2}{*}{ Metal matrix Fe/Ni vol\% } & \multicolumn{3}{|c|}{ Composition of metal matrix wt.\% } \\
\hline & & & $\mathrm{Fe}$ & $\mathrm{Ni}$ & $\mathrm{C}$ \\
\hline $15 \mathrm{FeNi}$ & 85 & 15 & 85 & 15 & \\
\hline 15FeNiC & 85 & 15 & 85 & 15 & +0.5 \\
\hline 20FeNi & 80 & 20 & 85 & 15 & \\
\hline 20FeNiC & 80 & 20 & 85 & 15 & +0.5 \\
\hline
\end{tabular}

Slurries containing 100\% Fe, 85/15 wt\% Fe/Ni and 100\% Ti(C,N) were considered for the study of rheology. Viscosity as a function of solid loading was measured using a Haake Mars rheometer (Thermo Scientific, Germany) with a double cone plate fix of $60 \mathrm{~mm}$ of diameter and angle of $2^{\circ}\left(\mathrm{DC} 60 / 2^{\circ}\right)$. Tests were per formed in a control rate mode shearing from 0 to $1000 \mathrm{~s}^{-1}$ in $2 \mathrm{~min}$, dwelling at $1000 \mathrm{~s}^{-1}$ for $1 \mathrm{~min}$ and shearing down to $0 \mathrm{~s}^{-1}$ in $2 \mathrm{~min}$ and control stress from 0 to $6 \mathrm{~Pa}$ in $2 \mathrm{~min}$ and down to $0 \mathrm{~Pa}$ in the same time. All tests were done at a constant temperature of $23 \pm 0.5^{\circ} \mathrm{C}$. The applied high shear rates during up ramps were enough to achieve a reproducible slurry microstructure, dependent only on the slurry composition, but not on the slurry preparation history.

Stable aqueous suspensions were prepared to obtain bulk samples using a combination of colloidal and powder metallurgical techniques. The three processing routes chosen were: (i) Slip Casting (SC), (ii) Slip Casting followed by Cold Isostatic Pressing (SC CIP), and (iii) Spray Dry and Uniaxial Pressing (SDP). Fig. 1 illus trates a scheme of the different processing routes attempted in this work, which includes the steps of slurry preparation as well as the employed processes of shaping/compacting. A total of seven different cermet samples were obtained, combining processing route and metal content (with and without $\mathrm{C}$ addition), as listed in Table 2. The conventional SC colloidal route consisted in the casting of slurries using a porous alumina mold. For the SC CIP samples powder metallurgical techniques were implemented in order to evaluate the synergistic effect of the combination of both routes. In this process, the SC green samples were pressed using the cold isostatic pressing process to evaluate the effect of increasing the
Table 2

Identification of samples prepared for each route and composition.

\begin{tabular}{lllll}
\hline Route & Composition & & & \\
\cline { 2 - 5 } & $15 \mathrm{FeNi}$ & 15FeNiC & 20FeNi & 20FeNiC \\
\hline SC & a & SC 15FeNiC & & \\
SC-CIP & SC-CIP 15FeNi & SC-CIP 15FeNiC & & \\
SDP & SDP 15FeNi & SDP 15FeNiC & SDP 20FeNi & SDP 20FeNiC \\
\hline
\end{tabular}

a SC-15FeNi samples break during sintering.

green density in the final properties of the sintered materials. For the SDP samples, the slurries were spray dried using an atomizer LabPlant SD 05 (North Yorkshire, United Kingdom) with the main controlled operating parameters such as the temperature at the inlet $\left(190^{\circ} \mathrm{C}\right)$ and at the exhaust $\left(100^{\circ} \mathrm{C}\right)$, the slurry pump rate $(2 \mathrm{~L} /$ $\mathrm{h})$, the air flow rate $\left(29 \mathrm{~m}^{3} / \mathrm{h}\right)$, and the atomizing nozzle design set to provide spherical agglomerates with high compressibility able to be shaped by uniaxial pressing [33]. Subsequently, granules were pressed at $600 \mathrm{MPa}$ in a uniaxial die into cylinders of $16 \mathrm{~mm}$ in diameter. Before the spray drying step and after milling, $2 \mathrm{wt} \%$ of polyvinyl alcohol (PVA) was added as binder. After PVA addition the slurry remained 20 min under mechanical stirring before being sprayed.

\subsection{Thermal analysis and microstructural and mechanical characterization of cermets}

The thermal behavior of SDP $15 \mathrm{FeNi}$ samples was investigated by dilatometry analysis at constant heating rate (CHR) in a push rod

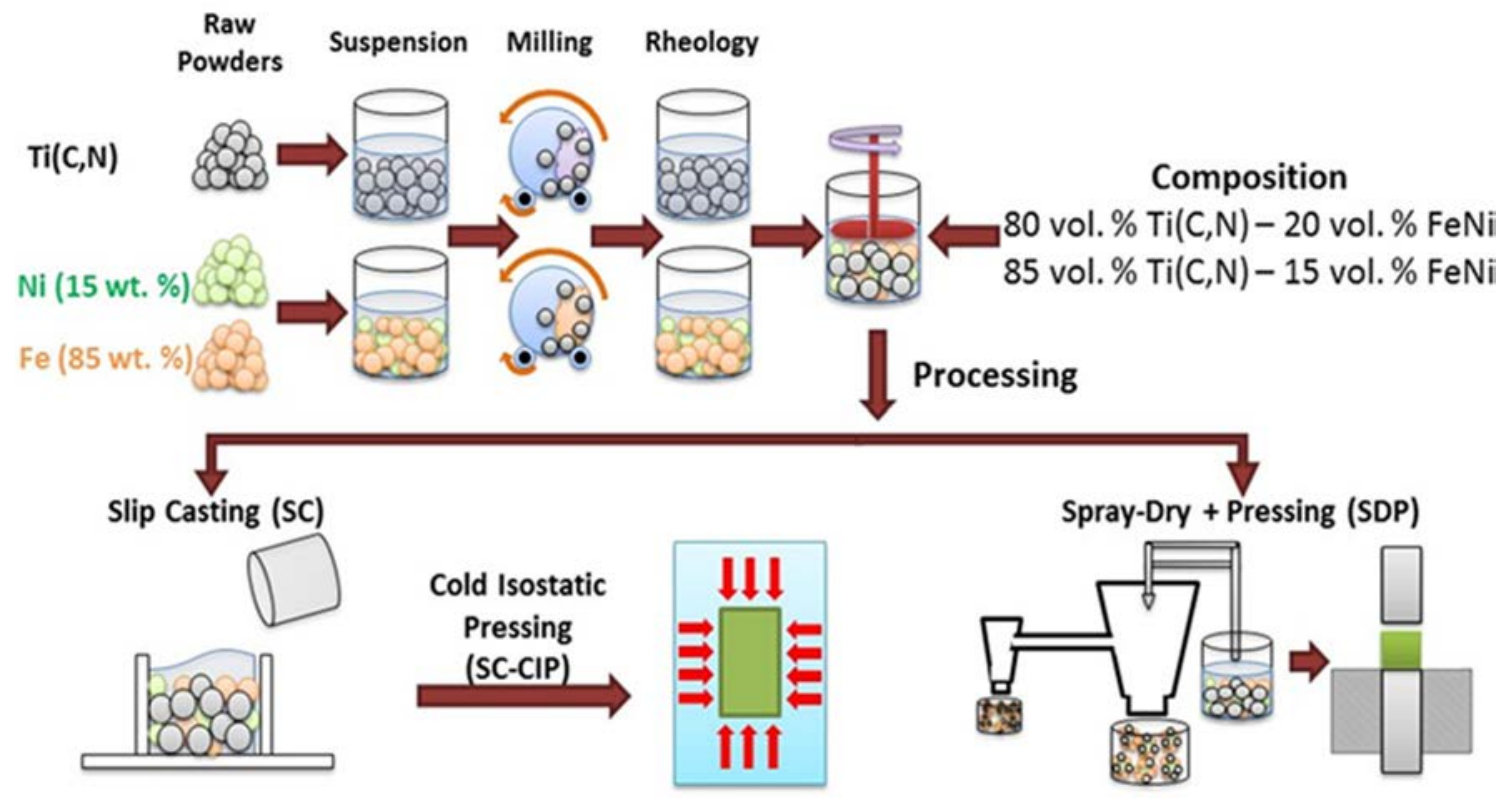

Fig. 1. Schematic of the different processing routes including the steps of slurry preparation as well as the employed processes of shaping/compacting. 
relative dilatometer model 402E/7 (Netzsch, Germany). Tests were performed under $\mathrm{Ar}$ atmosphere at temperatures up to $1450{ }^{\circ} \mathrm{C}$ at a heating/cooling rate of $5{ }^{\circ} \mathrm{C} / \mathrm{min}$. Temperature was held constant for $5 \mathrm{~min}$ and then cooled down to room temperature. Specimens used in the thermal analyses were pre sintered at $800^{\circ} \mathrm{C}$ for $30 \mathrm{~min}$ under vacuum $\left(10^{-5}\right.$ mbar $)$ and reducing $\left(\mathrm{N}_{2} / 10 \% \mathrm{H}_{2}\right)$ atmospheres (heating/cooling rates of $5^{\circ} \mathrm{C} / \mathrm{min}$ ) in order to eliminate the organic additives.

Further sintering of the green samples was performed using a high vacuum $\left(10^{-5} \mathrm{mbar}\right)$ tube furnace. All thermal treatments included a dwell at $800{ }^{\circ} \mathrm{C}$ for $30 \mathrm{~min}$. Sintering was conducted up to $1450{ }^{\circ} \mathrm{C}$ for different times (i.e. $60 \mathrm{~min}, 120 \mathrm{~min}$ and $300 \mathrm{~min}$ ), in order to study the effects of sintering time on the densification behavior and microstructural development of the materials. In all cases, a constant heating/cooling rate of $5{ }^{\circ} \mathrm{C} / \mathrm{min}$ was used.

The green density of the compacts was calculated from dimensional measurements and data expressed as relative density in relation to the theoretical one (calculated from the rule of mix tures). Density of sintered samples was measured using an Accupyc Helium Pycnometer (Micrometrics, USA) and by the Archimedes method using Eq. (1), where $m_{\text {air }}$ and $m_{\text {water }}$ means the medium in which the measurement was done.

$\rho_{\text {Archimedes }} \quad \rho_{\text {th }} \cdot \frac{m_{\text {air }}}{m_{\text {air }} m_{\text {water }}}$

Close porosity (referred to as $P_{\text {Close }}$ ) was estimated as the devi ation between the theoretical and pycnometric densities deter mined for each sintered material. On the other hand, the open porosity (named $P_{\text {Open }}$ ) of the samples was determined through the deviation between the Archimedes and pycnometric densities. Oxygen content of the green and sintered samples was measured with a LECO TC 500 (Michigan, USA).

Phase identification was carried out by $X$ ray diffraction (XRD, Siemens Bruker D8 Advance Diffractometer, Germany) using $\mathrm{Cu} \mathrm{K} \alpha$ radiation ( $\lambda \quad 1.540598 \AA)$. The diffraction patterns were measured step by step $\left(0.05^{\circ}\right.$ in $\left.2 \theta\right)$.

Morphology of the commercial powders, granules, as well as the microstructure of the sintered bulk pieces were examined using a XL 30 Scanning Electron Microscope (Philips, Netherlands). Image analysis was performed by Image $\mathrm{J}$, a public domain Java image processing and analysis software.

Vickers hardness of the sintered samples was measured with a pyramidal diamond indenter (Zwick/Roell, Model 3212, Ulm, Ger many) using $5 \mathrm{~kg}$ (HV5), $10 \mathrm{~kg}$ (HV10), $20 \mathrm{~kg}$ (HV20) and $30 \mathrm{~kg}$ (HV30) of load during $10 \mathrm{~s}$. At least 5 indentations per load and sample were performed. Indentations were examined with an optical microscope BX50 (Olympus, Japan). The diagonals of the indentation imprint, $d_{\mathrm{m}}$ (in $\mathrm{mm}$ ), were measured for every inden tation load, $P$ (in $\mathrm{N}$ ) and the hardness was evaluated according to:

$$
\text { HV } \quad 0.1854 \cdot \frac{P(N)}{d_{m}\left(m m^{2}\right)}
$$

\section{Results and discussion}

\subsection{Dispersion and rheological behavior of $\mathrm{Ti}(\mathrm{C}, \mathrm{N}) \mathrm{Fe} / \mathrm{Ni}$ slurries}

Morphological and micrographic characterizations of the as received powders are shown in Table 3 and Fig. 2 respectively. $\mathrm{Ti}(\mathrm{C}, \mathrm{N})$ particles show an irregular morphology with a wide particle size distribution determined by Dynamic light scattering (DLS) (Fig. $2 \mathrm{~d}$ ), being the average particle size in volume $2.1 \mu \mathrm{m}\left(\mathrm{D}_{\mathrm{v} 50}\right)$. This distribution is skewed to the right leading to maximum particle size of $10 \mu \mathrm{m}$, while the fine fraction achieved $0.3 \mu \mathrm{m}$. Fe particles show a spherical morphology with a bimodal distribution curve with particles sizes ranging from $1 \mu \mathrm{m}$ to $100 \mu \mathrm{m}$ with their average volume particle size stablished in $3.5 \mu \mathrm{m}\left(D_{v 50}\right)$. Finally, $\mathrm{Ni}$ powders have the finest morphology. The inset in Fig. 2c evidences the irregular thread like morphology of $\mathrm{Ni}$ and reveals the presence of a small fraction of nanoparticles. This powder exhibits the lowest average particle size in volume where the main population has a $D_{v 50}$ of $1 \mu \mathrm{m}$. The bimodal distribution also confirms the presence of a relevant amount of $\mathrm{Ni}$ nanoparticles in the powder [36]. The irregular shaped powders, $\mathrm{Ti}(\mathrm{C}, \mathrm{N})$ and $\mathrm{Ni}$, have a relatively high specific surface area (Table 3 ) for micrometric particles, due to the presence of a wide fine fraction of powders in the case of $\operatorname{Ti}(\mathrm{C}, \mathrm{N})$, and the nanoparticles as well as the thread like morphology of $\mathrm{Ni}$. Both details are evidenced in the micrographs shown in Fig. 2 a and c, respectively.

The Brunauer-Emmett-Teller (BET) diameter ( $\mathrm{D}_{\mathrm{BET}}$ ) calculated, assuming spherical, homogeneous primary particles (using the equation $D_{\mathrm{BET}} \quad 6 /(\mathrm{SSA} \cdot \rho)$, where $\mathrm{SS}_{\mathrm{A}}$ is the specific surface area and $\rho$ is the density) will allow us to calculate the agglomeration factor, $F_{a g}\left(D_{v 50} / D_{B E T}\right)$. This parameter is indicative of the state of agglomeration of the powder. As it is clearly seen, the greater agglomeration factor of the Ni particles is a consequence of their low particle size and the irregular thread like morphology and thus will cause relevant drawbacks during the colloidal processing of the slurries as will be shown below.

The solid content of monophasic slurries was optimized in terms of rheology. In the microstructure of a slurry, the distance between the particles decreases when the solids content increases, causing an increment of the particle particle interactions, thus difficulting the flow. In colloidal processing, there is a direct relationship be tween the packaging density of the monolith and the flow behavior of the slurry, where the maximum amount of powder in the slurry is desirable to achieve the maximum packing density, always keeping an adequate viscosity for casting. In order to select the optimal solid content to formulate the slurries to shape composites, the flow curves of the $\mathrm{Ti}(\mathrm{C}, \mathrm{N}), \mathrm{Fe}$ and $\mathrm{Fe} / \mathrm{Ni}(85 / 15 \mathrm{wt} \%)$ slurries were recorded when the solid content increased up to 50-60 vol\%. Fig. 3 shows the variation of the viscosity for a shear rate of $100 \mathrm{~s}^{-1}$ versus the volumetric solid fraction $(0.20<\varphi<0.60)$ of the aforementioned slurries (Fig. 3a) as well as the flow curves of the $\mathrm{Ti}(\mathrm{C}, \mathrm{N})$ and $\mathrm{Fe} / \mathrm{Ni}$ slurries for the optimized solid content (Fig. 3b).

The results plotted in Fig. 3a correspond to a distribution described by the modified Krieger-Dougherty model, which allows predicting the maximum packing fraction $(\varphi \mathrm{m})$ achieved for a dispersed and stabilized slurry of particles.

$\eta \quad\left(1 \frac{\varphi}{\varphi_{\mathrm{m}}}\right)^{-[\eta] \varphi_{\mathrm{m}}}$

where $\eta$ is the relative viscosity at $100 \mathrm{~s}^{-1}$ and $[\eta]$ is the intrinsic viscosity. The exponent is commonly substituted by $\mathrm{n}$ which is a value dependent on the shape of the particles. For all systems, the adjusted parameters of the Krieger-Dougherty model are included at the inset in Fig. 3a. As it can be observed in the referred figure, the wide particle size distribution of the $\mathrm{Ti}(\mathrm{C}, \mathrm{N})$ powders ranging $0.2 \mu \mathrm{m}<\mathrm{D}_{\mathrm{v}}<1 \mu \mathrm{m}$ (see Fig. 2a and d) allows to reach a higher packing fraction $(\varphi \mathrm{m}, \mathrm{Ti}(\mathrm{C}, \mathrm{N}) \quad 0.65)$ than for the Fe and Fe/Ni par ticles $(\varphi \mathrm{m}, \mathrm{Fe} \quad 0.50$ and $\varphi \mathrm{m}, \mathrm{Fe} / \mathrm{Ni} \quad 0.40)$.

It is crucial to provide an adequate adjustment of the solid content to the slurries because if this value is too high, slurries will have an inadequate viscosity for its posterior processing, whereas if the value is too low, the suspension will show density and packing drawbacks. Thus, based upon the results in Fig. 3a, Ti(C,N) slurries 
Table 3

Physical characterization of the as-received powders.

\begin{tabular}{|c|c|c|c|c|c|}
\hline \multirow[t]{2}{*}{ Powder } & \multicolumn{3}{|l|}{ Size } & \multirow[t]{2}{*}{$\operatorname{Density}^{\mathrm{a}}\left(\mathrm{g} / \mathrm{cm}^{3}\right)$} & \multirow[t]{2}{*}{ Specific Surface Area ${ }^{\mathrm{b}}\left(\mathrm{m}^{2} / \mathrm{g}\right)$} \\
\hline & $\mathrm{D}_{\mathrm{v} 50}(\mu \mathrm{m})$ & $\mathrm{D}_{\mathrm{BET}}(\mu \mathrm{m})$ & $\mathrm{F}_{\mathrm{ag}}$ & & \\
\hline $\operatorname{Ti}(C, N)$ & 2.1 & 0.4 & 5 & 5.1 & 3.0 \\
\hline $\mathrm{Fe}$ & 3.5 & 1.2 & 3 & 7.8 & 0.6 \\
\hline $\mathrm{Ni}$ & 1.0 & 0.2 & 10 & 8.9 & 4.0 \\
\hline
\end{tabular}

\pm 0.1 Standard deviation in density measurements.

b \pm 0.1 Standard deviation in specific surface area measurements.
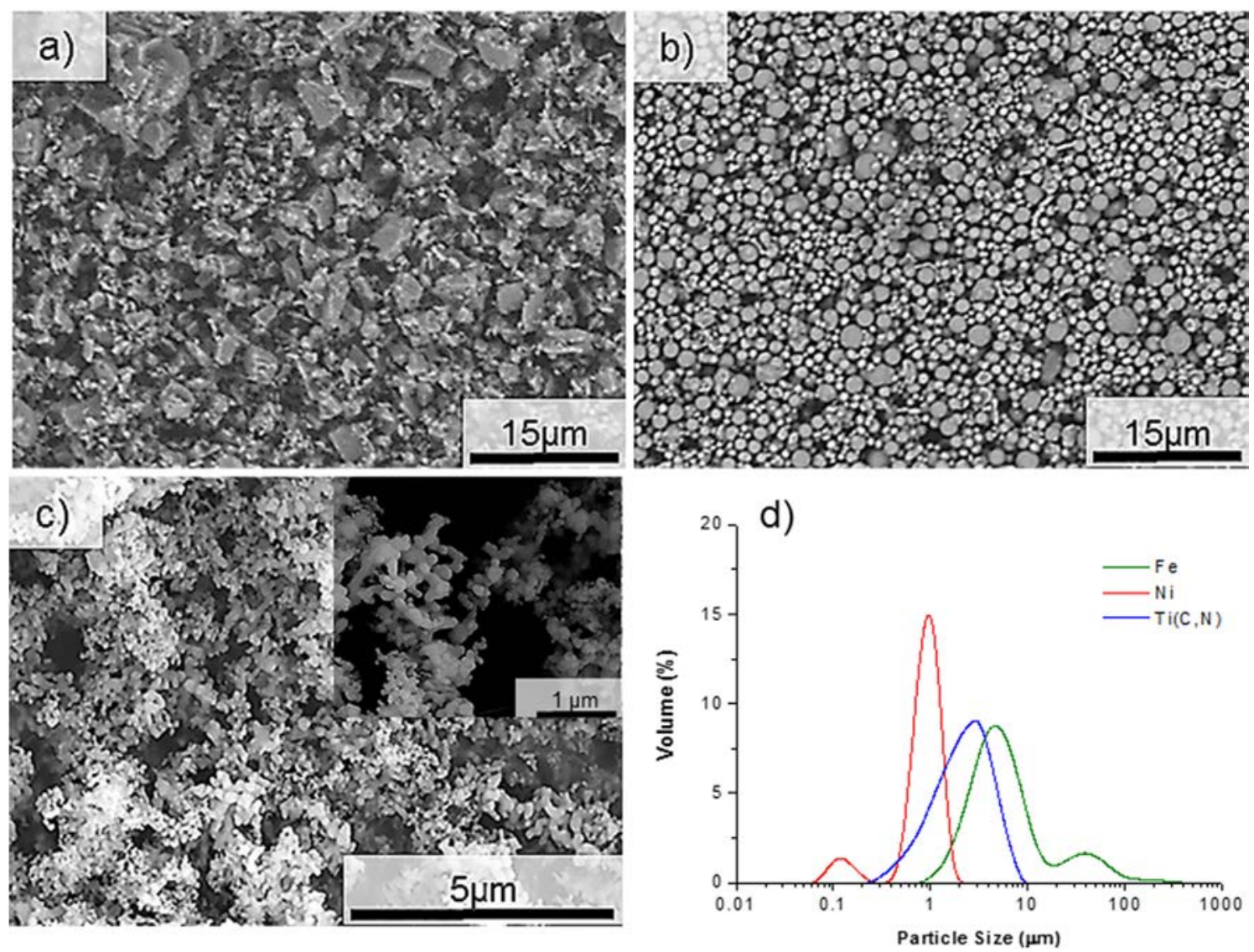

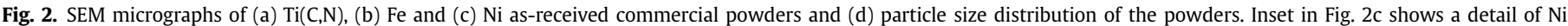
powder.

with a $45 \mathrm{vol} \%$ of solid content and a relatively low viscosity of $\sim 30 \mathrm{mPa}$ s were prepared in order to avoid the rheological effect of the $\mathrm{Ni}$ addition to the Fe suspension. The $\mathrm{n}$ value of the spherical $\mathrm{Fe}$ particles slurry stablished at 2.5 , changed to 3.5 at the $\mathrm{Fe} / \mathrm{Ni}$ sus pensions due to the thread like morphology of the Ni. Moreover, the maximum packing fraction $(\varphi \mathrm{m})$ also decreased from $50 \mathrm{vol} \%$ to $40 \mathrm{vol} \%$. This phenomenon is directly related to the Ni nanoparticles tendency to agglomerate (high $\mathrm{F}_{\mathrm{ag}}$ in Table 3 ) and the effect of its thread like morphology at the slurry flux. Finally, a 35 vol\% solid content for the Fe/Ni slurry was chosen even though this value has a slightly higher viscosity (144 $\mathrm{mPa}$ s) than the accepted processing limit for casting that is fixed around $100 \mathrm{mPa}$ s for a shear of $100 \mathrm{~s}^{-1}$. In the minor component of the composite, it is permissible, to work with slightly higher viscosities than that stablished, because it will be compensated by the low viscosity obtained in the $45 \mathrm{vol} \% \mathrm{Ti}(\mathrm{C}, \mathrm{N})$ slurry (30 mPa s).

Fig. 3b shows the flow curves of the $\mathrm{Ti}(\mathrm{C}, \mathrm{N})$ and $\mathrm{Fe} / \mathrm{Ni}$ suspen sions for the solid content selected to work with, $45 \mathrm{vol} \%$ and $35 \mathrm{vol}$
\% respectively. All slurries exhibit shear thinning behavior (pseu doplastic). It means that viscosity decreases under shear strain. As expected, the wide particle size distribution of the $\mathrm{Ti}(\mathrm{C}, \mathrm{N})$ powder provides lower viscosities than the $\mathrm{Fe} / \mathrm{Ni}$ mixture. The pseudo plasticity provides to the slurry a high viscosity at rest hindering particles settling and segregation, and then maintaining the ho mogeneity of the mixture.

The slurries prepared were casted in porous alumina molds to obtain the SC samples. Some of them were pressed by cold isostatic pressing giving the SC CIP cermet samples. In addition, selected slurries were spray dried after PVA addition (2 wt\%) to shape granules for further compacting by uniaxial pressing to fabricate SDP samples. The granules obtained for the $15 \mathrm{FeNi}$ suspension (Table 1) are shown in Fig. 4 at different magnifications. Micro graphs suggest the co existence of both ceramic and metallic phases homogeneously mixed and distributed in the compact and dense granules. The minimum and maximum sizes determined for these granules at the micrographs are $15 \mu \mathrm{m}$ and $50 \mu \mathrm{m}$, most of 

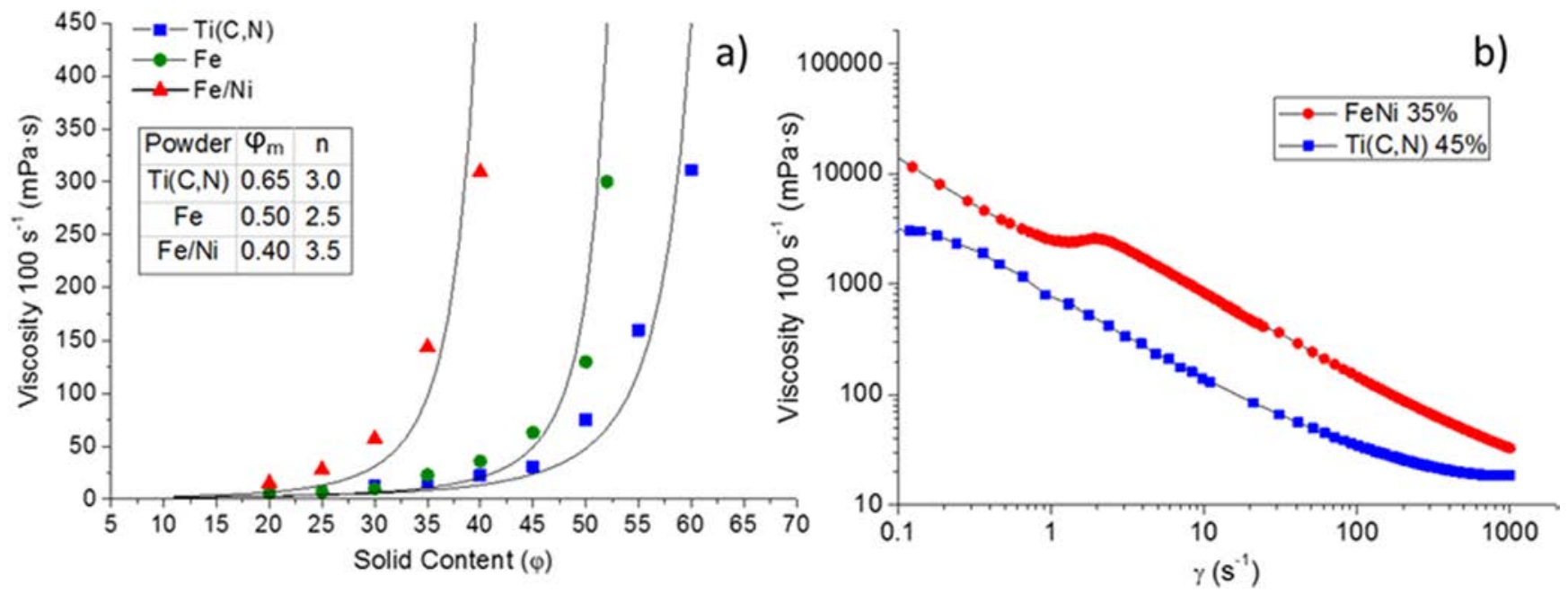

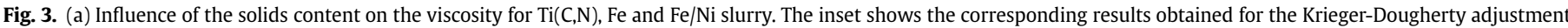
and (b) Flow curves of FeNi 35 vol\% and Ti(C,N) 45 vol\%.
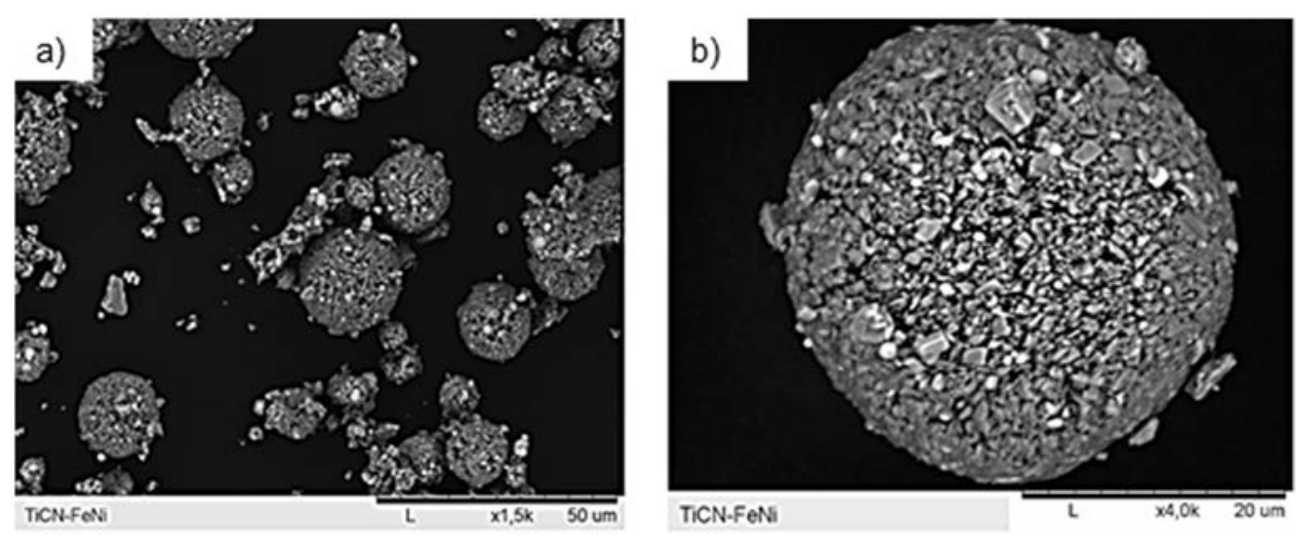

Fig. 4. SEM micrographs of the $15 \mathrm{FeNi}$ granules obtained by spray-drying.

them ranging between 15 and $25 \mu \mathrm{m}$. A study of compressibility of the granules was carried out applying pressures from 400 to $800 \mathrm{MPa}$ (not shown here). Granules improves the compressibility if it is compared with as received powders leading to an uniform and homogeneous phase distribution in the green compacts after pressing, avoiding the agglomeration of $\mathrm{Ti}(\mathrm{C}, \mathrm{N})$ reinforcement particles, as well as reaching relatively high values of green density, ranging between 65 and $69 \%$.
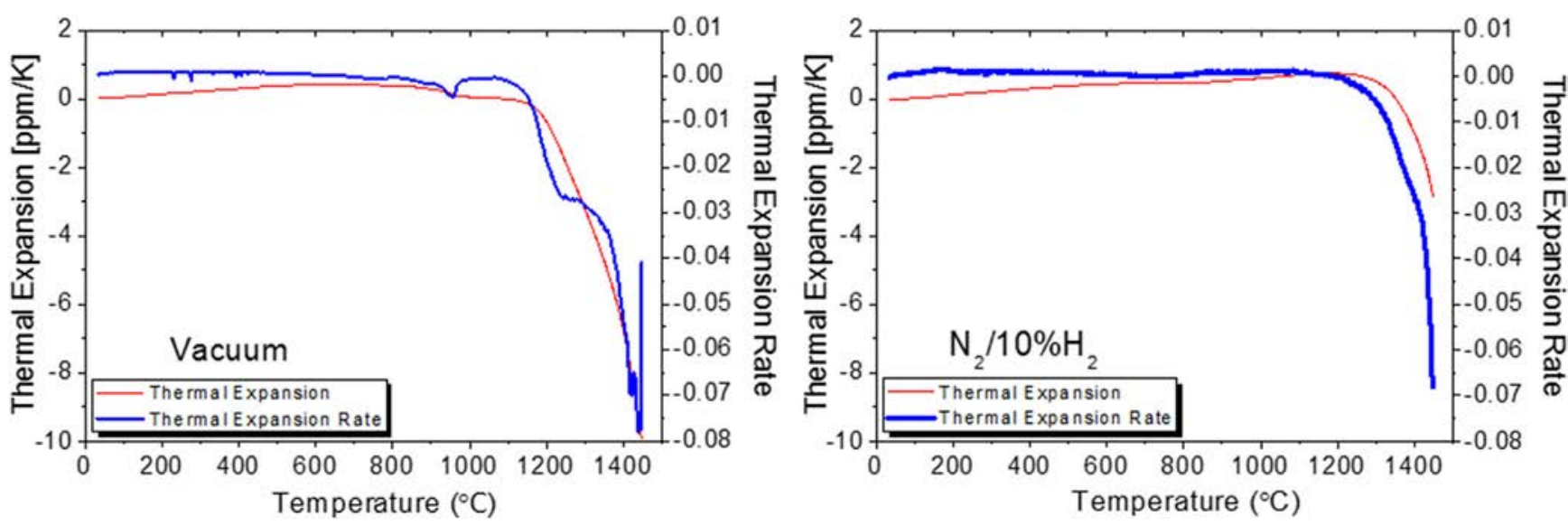

Fig. 5. Thermal expansion $(\Delta \mathrm{l} / \mathrm{l})$ and thermal expansion rate $(\Delta \mathrm{l} / \Delta \mathrm{t})$ versus temperature for samples pre-sintered under: (a) vacuum $(\mathrm{b}) \mathrm{N}_{2} / 10 \% \mathrm{H}_{2}$. 


\subsection{Thermal analysis and characterization of bulk pieces}

Fig. 5 shows the dilatometry results of the SDP 15 FeNi samples pre sintered in vacuum and under reducing atmosphere. It can be observed that the characteristic shrinkage of the samples is different depending on the atmosphere used for the pre sintering step. In the case of the samples pre sintered in vacuum, a slight increase in thermal expansion is observed up to $\sim 775^{\circ} \mathrm{C}$. Beyond this temperature the sample starts shrinking, with three different slopes being evident corresponding to diverse thermal phenomena. First, the specimen shrinks at a relatively slow rate as the tem perature increases, exhibiting a minimum in the thermal expansion curve at $\sim 950^{\circ} \mathrm{C}$. This effect may be ascribed to the reduction of the titanium oxide passivation layer of $\mathrm{Ti}(\mathrm{C}, \mathrm{N})$ particles [37]. Further shrinkage has a sharply rate, exhibiting a minimum in the curve at $1250{ }^{\circ} \mathrm{C}$. This could be associated with solid state reactions during the thermal rearrangement of the metal powder particles [36] and the formation of the FeNi alloy. Finally a later inflexion point can be observed at the dilatometric curve at $1420-1440{ }^{\circ} \mathrm{C}$, which could be related to the early liquid phase diffusion process of the metal phase [10]. The liquid phase formation of FeNi evolves from $1498^{\circ} \mathrm{C}$ (melting point) to $1478{ }^{\circ} \mathrm{C}$, due to the high wettability of Ni over $\mathrm{Ti}(\mathrm{C}, \mathrm{N})$ particles.

In the case of samples pre sintered in a $\left(\mathrm{N}_{2} 10 \% \mathrm{H}_{2}\right)$ reducing atmosphere a thermal expansion up to $1250{ }^{\circ} \mathrm{C}$ is observed, fol lowed by a continuous shrinkage up to $1450{ }^{\circ} \mathrm{C}$. The absence of a minimum in the thermal expansion curve indicates that maximum sintering has not yet been achieved at $1450{ }^{\circ} \mathrm{C}$. This effect could be attributed to the higher oxidation state of the sample pre sintered under reducing atmosphere, as the event corresponding to the reduction of oxides observed in the former case is not observed. For this reason an analysis of the oxygen content in the samples before and after the heat treatment was carried out (see Table 4). The oxygen content of the samples pre sintered in reducing atmo sphere is higher (1.69 wt\%) than samples pre sintered in vacuum (0.82 wt\%), being the initial oxygen content (1.58 wt\%) for green samples. Unexpectedly, the reduction of the oxides on the particles surface was more activated in vacuum than under reducing atmo sphere. This can be due to the presence of $\mathrm{N}_{2}$ in the atmosphere during the pre sintering process of these composites, playing an important role in the densification of the sample. An increase in the $\mathrm{N}_{2}$ activity could promote its solution in the $\mathrm{Ti}(\mathrm{C}, \mathrm{N})$ structure causing the $C$ depletion, as reported elsewhere [37,39]. The pres ence of $\mathrm{N}_{2}$ could inhibit the reduction of oxides and change the sintering behavior of the cermet. Consequently it can be concluded that the sintering under vacuum atmosphere was activated due to the absence of oxides in the surface of the particles that leaves a higher free area of interaction between them.

Based upon these findings, in order to study the effect of sin tering time on the densification behavior of the materials, sintering of the green samples were performed under vacuum $\left(10^{-5} \mathrm{mbar}\right)$ at
$1450{ }^{\circ} \mathrm{C}$ for different times $(60,120$ and $300 \mathrm{~min})$ and constant heating/cooling rate of $5{ }^{\circ} \mathrm{C} / \mathrm{min}$. The green density ( $\left.\rho_{\text {green }}\right)$ of the initial SDP samples was $68.8 \%$ of the theoretical density determined by the rule of mixture.

Table 4 summarizes the densities determined by He picnometry $\left(\rho_{\mathrm{He}}\right)$ and Archimedes method $\left(\rho_{\text {Arq }}\right)$, close and open porosities ( $P_{\text {close }}$ and $P_{\text {open }}$, respectively), $\mathrm{O}_{2}$ content (wt.\%), dimensional variation in the sample diameter $(\Delta \mathrm{l})$ and weight changes $(\Delta \mathrm{m})$ of the thermally treated specimens. Samples sintered during $60 \mathrm{~min}$ reached densities of $96.3 \%$ of the theoretical. Therefore this sin tering time is not enough to get a full dense material. Fig. 6a shows a micrograph of a sample, where two phases can be clearly iden tified in the cermet: the bright contrast phase corresponds to the FeNi matrix, whereas the darker phase corresponds to the ceramic $\mathrm{Ti}(\mathrm{C}, \mathrm{N})$ phase. During liquid phase sintering the metal phase sur rounds the $\mathrm{Ti}(\mathrm{C}, \mathrm{N})$ particles, but the ceramic phase is not completely sintered. By contrast, sintering times of 120 min lead to almost full density ( 99\%), as can also be evidenced in Fig. $6 \mathrm{~b}$. In this case, after sintering, Ti(C,N) particles were observed to be perfectly embedded in the metal matrix and only small residual porosity can be observed in triple points. Interestingly, longer sintering times of $300 \mathrm{~min}$ do not result in higher densities $(94.4 \%$ of the theoretical density), which can be related with an evident deficiency of metal phase in the microstructure, as can be observed in Fig. 6c. These results evidence a "sintering time threshold", above which the densification of this complex composite decreases. This phenom enon may be explained by the sublimation of the metal phase, evidenced by the significant mass loss, $\Delta \mathrm{m}$, of $21.8 \%$, as reported in Table 4 , together with the relatively high dimensional change; the latter cannot be ascribed only to the sintering shrinkage taking into account density values in Table 4 and the microstructure in Fig. 6c. In fact, it has been reported that the vapor pressure of $\mathrm{Ni}$ (ten times higher than $\mathrm{Co}$ ) causes considerable mass loss during sintering at temperatures around $1000{ }^{\circ} \mathrm{C}$ for a $10^{-5}$ mbar [40]. These condi tions match our sintering temperature and pressure and, conse quently, the mass loss of our samples could be attributed to the $\mathrm{Ni}$ sublimation.

Based upon such counterbalance effects, a compromise between densification and mass loss must be attained in order to achieve full density materials with the desired composition. This balance was found in samples with 120 min of sintering time, where the highest density with moderate mass loss was measured (see Table 4). The dimensional variation of the samples followed the same trend as the mass variation. It is worth pointing out that the oxygen content of the different sintered samples was kept constant at around $0.2 \mathrm{wt} \%$.

Finally, in order to verify the results obtained, XRD character ization of the three samples were carried out. Fig. 7 shows the spectra associated with the $\mathrm{Ti}(\mathrm{C}, \mathrm{N})$ reinforcement and the main peak of the metallic matrix FeNi phase (also magnified at the inset). Although the presence of $\mathrm{FeNi}$ is evidenced in all samples,

Table 4

Characterization of SDP $15 \mathrm{FeNi}$ samples for a sintering cycle at $800{ }^{\circ} \mathrm{C}$ for $30 \mathrm{~min}$ and $1450{ }^{\circ} \mathrm{C}$ for different times under vacuum.

\begin{tabular}{|c|c|c|c|c|c|c|c|c|}
\hline \multirow[t]{2}{*}{ Sintering Time [min] } & \multicolumn{3}{|c|}{ Density [\% th] } & \multicolumn{2}{|c|}{ Porosity $^{\mathrm{a}}[\%]$} & \multirow[t]{2}{*}{$\mathrm{O}_{2}$ wt.\% } & \multirow[t]{2}{*}{ Dimensional Variation, $\Delta \mathrm{l}[\%]$} & \multirow[t]{2}{*}{ Mass Loss, $\Delta \mathrm{m}[\%]$} \\
\hline & $\rho^{\mathrm{a}}$ green & $\rho^{\mathrm{b}} \mathrm{He}$ & $\rho^{\mathrm{b}}$ Arq. & & & & & \\
\hline \multirow[t]{2}{*}{60} & 68.80 & 96.3 & 95.1 & $P_{\text {close }}$ & 3.70 & $0.23 \pm 0.04$ & $-11.9 \pm 0.6$ & $-3.3 \pm 0.2$ \\
\hline & & & & $\mathrm{P}_{\text {open }}$ & 1.23 & & & \\
\hline \multirow[t]{2}{*}{120} & & 98.9 & 98.8 & Pclose & 1.14 & $0.21 \pm 0.05$ & $-14.6 \pm 0.4$ & $-8.8 \pm 0.1$ \\
\hline & & & & $\mathrm{P}_{\text {open }}$ & 0.01 & & & \\
\hline \multirow[t]{2}{*}{300} & & 94.4 & 93.7 & $P_{\text {close }}$ & 5.57 & $0.27 \pm 0.06$ & $-17.3 \pm 0.1$ & $-21.8 \pm 0.3$ \\
\hline & & & & $P_{\text {open }}$ & 0.71 & & & \\
\hline
\end{tabular}

a $0.1 \%$ Standard deviation in green density measurements.

b $0.01 \%$ Standard deviation in sintered density measurements. 

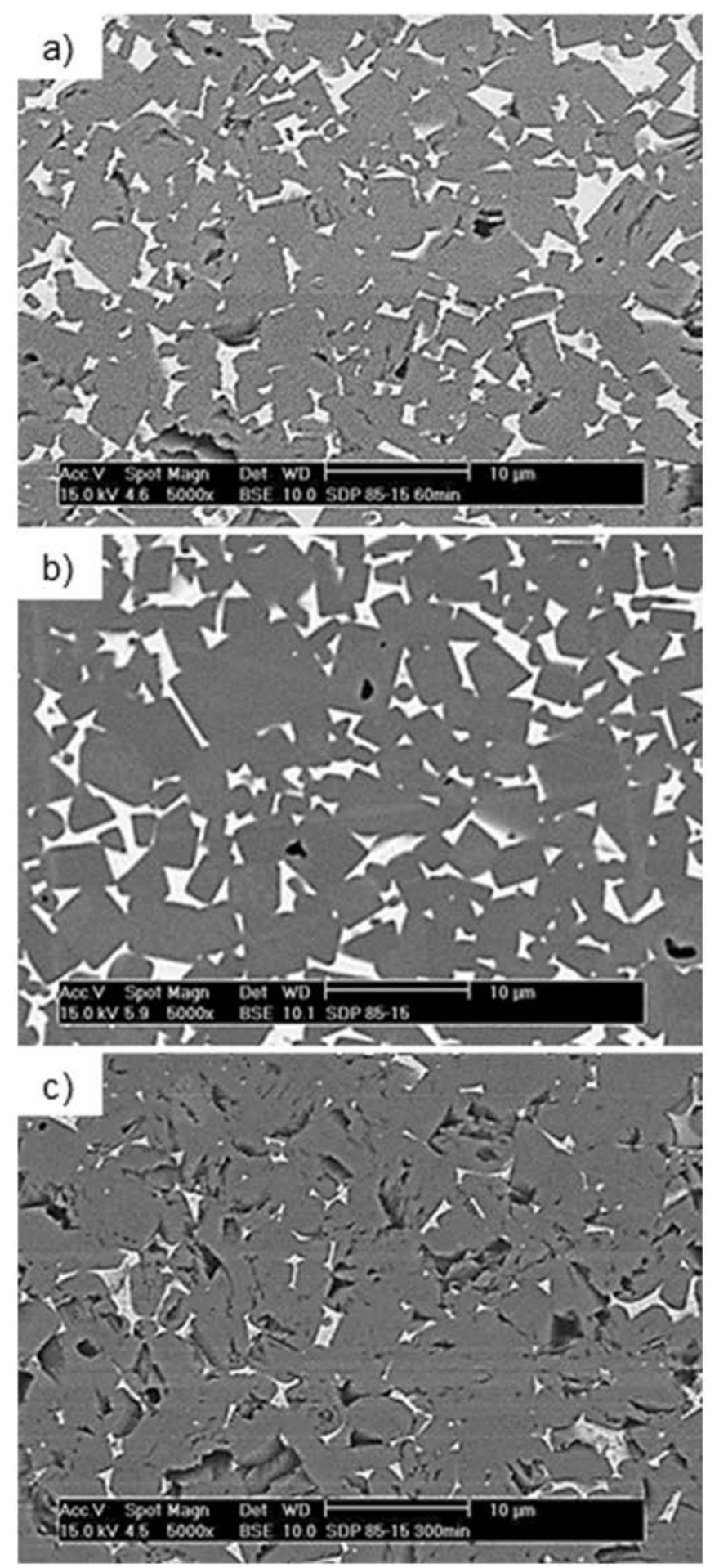

Fig. 6. SEM micrographs of $\mathrm{Ti}(\mathrm{C}, \mathrm{N})$-based cermets (SDP $15 \mathrm{FeNi})$ sintered for different times: (a) $60 \mathrm{~min} \mathrm{(b)} 120 \mathrm{~min}$ and (c) $300 \mathrm{~min}$.

variations in the peak intensity of FeNi phase suggest that different reinforcement/matrix ratios can be found depending on the sin tering time. Nevertheless, we should also take into account that the crystallization of the $\mathrm{Ti}(\mathrm{C}, \mathrm{N})$ grains will cause an increase in the intensity of their peaks as the sintering time increases. Thus, peaks of the minority phase, i.e. the metal phase, will be increasingly masked in the pattern. In addition, the inset in Fig. 7 shows a decrease of the intensity of the corresponding FeNi peak with the sintering time, thus reinforcing the hypothesis of the sublimating effect of Ni discussed above.

Based upon these findings, all green samples in Table 2 were sintered at $1450{ }^{\circ} \mathrm{C}$ for $120 \mathrm{~min}$ in vacuum with a 30 min dwell at $800{ }^{\circ} \mathrm{C}$. The green and sintered densities as well as the porosity values of the sintered samples are shown in Table 5. The highest values of green density are obtained for SDP samples, as expected, as they are produced by pressing of high compressibility granules. On the other hand, cold isostatic pressing (CIP) increases the green density of SC samples in about 15\%. Regarding the composition effect, increasing the amount of hard phase from $80 \mathrm{vol} \%$ to $85 \mathrm{vol} \%$ decreases the green density due to the higher hardness and stiff ness of the ceramic powder blend during pressing.

Fig. 8 shows the SEM micrographs corresponding to the different cermet samples. All micrographs evidence the presence of the same phases defined previously: the brighter phase is the FeNi matrix and the darker one corresponds to the ceramic phase, $\mathrm{Ti}(\mathrm{C}, \mathrm{N})$. In all cases $\mathrm{Ti}(\mathrm{C}, \mathrm{N})$ particles are surrounded by the metal matrix phase, which gives to the whole piece a metallic appearance despite the high ceramic content (80-85 vol\%). Although all mi crostructures exhibit a high dispersion of both phases, samples obtained through SDP show the most homogeneous dispersion of phases and lowest porosity. This may be due to the fact that the atomization of the slurry, through which granules are obtained, offers the possibility of pre designing the final composite in the granules helping to prevent further agglomeration of $\mathrm{Ti}(\mathrm{C}, \mathrm{N})$ rein forcement particles. This can also avoid metal pools like those observed in SC samples, which may formed during casting in SC and then in SC CIP samples.

In a general inspection of the microstructures, micrographs evidence that samples processed through SC (Fig. 8a) show a higher amount of porosity than SC CIP samples (Fig. 8b and c), that is in accordance to the values measured from the same composition (7.8\% and 3.66\%, respectively), confirming the beneficial effect of the CIP process. Regarding SDP samples (Fig. $8 \mathrm{~d}-\mathrm{g}$ ), a very low amount of porosity can be observed $(<1.81 \%)$, being the most dense materials those which have a higher amount of metal phase in the composition (with porosities $<1 \%$ ). In Table 5, porosity values also evidence that the compositions formulated with $C$ exhibit slightly lower densities in all cases.

On the other hand, differences in composition between the 15FeNi (Fig. 8d and e) and 20FeNi (Fig. 8 f and g) samples are easily evidenced by observing the higher amount of the ceramic phase at the microstructure; these data were also confirmed by results of the image analysis. In fact, the ceramic/metal balance as well as the porosity determined through the microstructural analysis of the samples in Fig. 7 is also listed in Table 5 for comparative purposes. Image analysis results show that SDP samples approach better the ceramic/metal balance formulated as the starting composition of the cermet (see experimental part). Deviations from the starting formulation are more evident as the porosity of the material in creases, as for SC and SC CIP samples. Although this could be associated with the accuracy of the image analysis, the porosity values determined approach in range those values obtained from the density measurements.

A Vickers hardness (HV) analysis was carried out for the sintered samples as a function of indentation load (HV5, HV10, HV20 and HV30). Table 6 represents the average hardness along with the standard deviation of at least 5 measurements performed on each sample. The total porosity $P_{\text {Tot }}$ of the different cermets is also collected in Table 6 for comparative purposes. Fig. 9 shows a series of HV30 representative imprints carried out on all samples.

A significant Indentation Size Effect (ISE) [41,42] was observed from HV5 to HV20 in all samples, where the measured Vickers hardness decreased significantly with the indentation load, while 


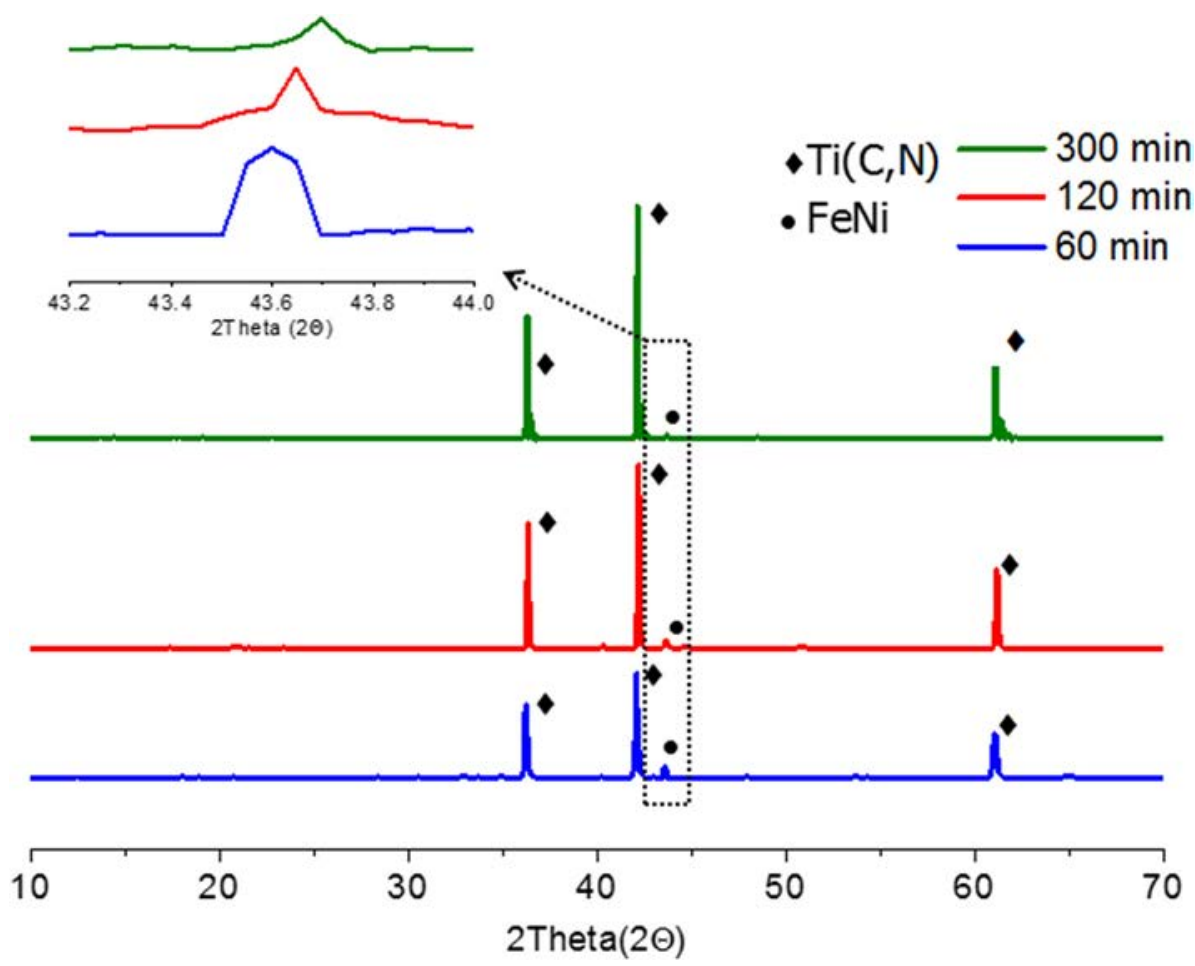

Fig. 7. X-ray difractograms recorded on the polished surface of SDP $15 F e N i$ samples sintered during different holding times.

Table 5

Density, porosity and ceramic/metal balance of sintered materials.

\begin{tabular}{|c|c|c|c|c|c|c|c|c|}
\hline \multirow[t]{2}{*}{ Sample } & \multicolumn{4}{|c|}{ Density (\% th) } & \multicolumn{3}{|c|}{ Porosity (\%) } & \multirow[t]{2}{*}{ Ceramic/metal balance [Porosity] (\%) } \\
\hline & $\rho_{\text {th }}$ & $\rho^{\mathrm{a}}$ green & $\rho^{\mathrm{b}} \mathrm{He}$ & $\rho^{\mathrm{b}}$ geo & $P_{\text {Tot }}$ & $P_{\text {Close }}$ & $P_{\text {Open }}$ & \\
\hline SC $15 \mathrm{FeNiC}$ & 5.53 & 57.3 & 93.10 & 92.20 & 7.80 & 6.90 & 0.80 & $72.3 / 21.0[6.7]$ \\
\hline SC-CIP $15 \mathrm{FeNi}$ & 5.53 & 66.7 & 97.66 & 97.25 & 2.75 & 2.44 & 0.31 & $81.3 / 15.9[2.8]$ \\
\hline SC-CIP 15FeNiC & 5.53 & 66.3 & 97.32 & 96.34 & 3.66 & 2.68 & 0.98 & $79.5 / 16.5[4.0]$ \\
\hline SDP $15 \mathrm{FeNi}$ & 5.53 & 68.8 & 98.86 & 98.85 & 1.15 & 1.14 & 0.01 & $83.6 / 15.8[0.6]$ \\
\hline SDP $15 \mathrm{FeNiC}$ & 5.53 & 68.3 & 98.40 & 98.19 & 1.81 & 1.60 & 0.21 & $83.4 / 15.0[1.6]$ \\
\hline SDP 20FeNi & 5.67 & 69.6 & 99.72 & 99.56 & 0.44 & 0.28 & 0.16 & $81.2 / 18.6[0.2]$ \\
\hline SDP $20 \mathrm{FeNiC}$ & 5.67 & 66.9 & 99.50 & 99.01 & 0.99 & 0.50 & 0.49 & $79.8 / 19.2[1.0]$ \\
\hline
\end{tabular}

a $0.1 \%$ Standard deviation in green density measurements.

b $0.01 \%$ Standard deviation in sintered density measurements.

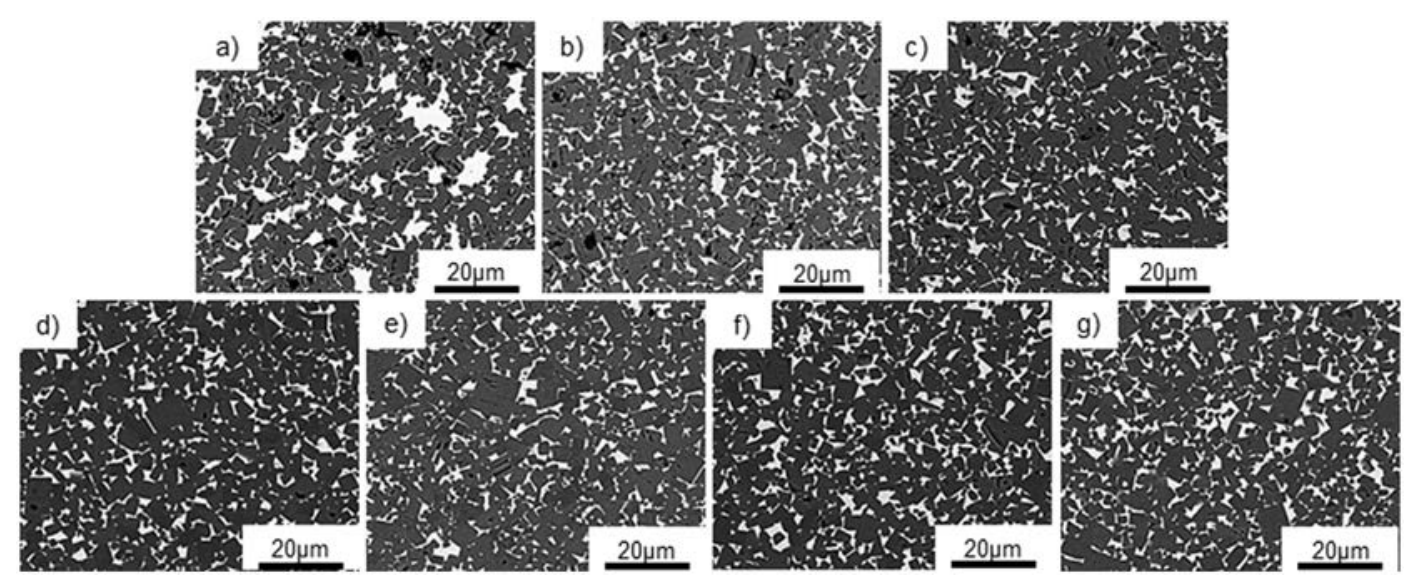

Fig. 8. SEM micrographs of Ti(C,N)-based cermets fabricated (a) SC 15FeNiC, (b) SC-CIP 15FeNi, (c) SC-CIP 15FeNiC, (d) SDP 15FeNi, (e) SDP 15FeNiC, (f) SDP 20FeNi and (g) SDP 20FeNiC. 
Table 6

Vickers Hardness measurements with different loads: HV5, HV10, HV20 and HV30. The total porosity $\left(P_{\text {Tot }}\right)$ is also shown for comparative purposes.

\begin{tabular}{llllll}
\hline Material & $\mathrm{P}_{\text {Tot }}$ & HV5 & HV10 & HV20 & HV30 \\
\hline SC 15FeNiC & 7.80 & $1039 \pm 100$ & $946 \pm 62$ & $958 \pm 57$ & $925 \pm 37$ \\
SC-CIP 15FeNi & 2.75 & $1198 \pm 30$ & $1111 \pm 57$ & $1127 \pm 42$ & $1137 \pm 50$ \\
SC-CIP 15FeNiC & 3.66 & $1326 \pm 47$ & $1227 \pm 36$ & $1219 \pm 41$ & $1219 \pm 22$ \\
SDP 15FeNi & 1.15 & $1313 \pm 18$ & $1281 \pm 14$ & $1258 \pm 17$ & $1246 \pm 18$ \\
SDP 15FeNiC & 1.81 & $1383 \pm 59$ & $1330 \pm 13$ & $1309 \pm 10$ & $1301 \pm 7$ \\
SDP 20FeNi & 0.44 & $1179 \pm 28$ & $1085 \pm 69$ & $1144 \pm 13$ & $1120 \pm 26$ \\
SDP 20FeNiC & 0.99 & $1267 \pm 27$ & $1207 \pm 27$ & $1198 \pm 9$ & $1185 \pm 7$ \\
\hline
\end{tabular}

which is to be related to deformation of the metal phase around the indentation [45]. This finding should be further investigated, although it is beyond the scope of this work.

Regarding the effect of $C$ addition, the increment of hardness has been also reported in literature for $\operatorname{Ti}(\mathrm{C}, \mathrm{N})$ with Fe based binders, although the effect may be more relevant when higher amount of metal binder is present [46]. The reason of this increment might be related to different factors that are currently under evaluation, which derive from the decrease of the liquidus temperature of the metallic matrix with the $C$ addition: (i) a different rearrangement of

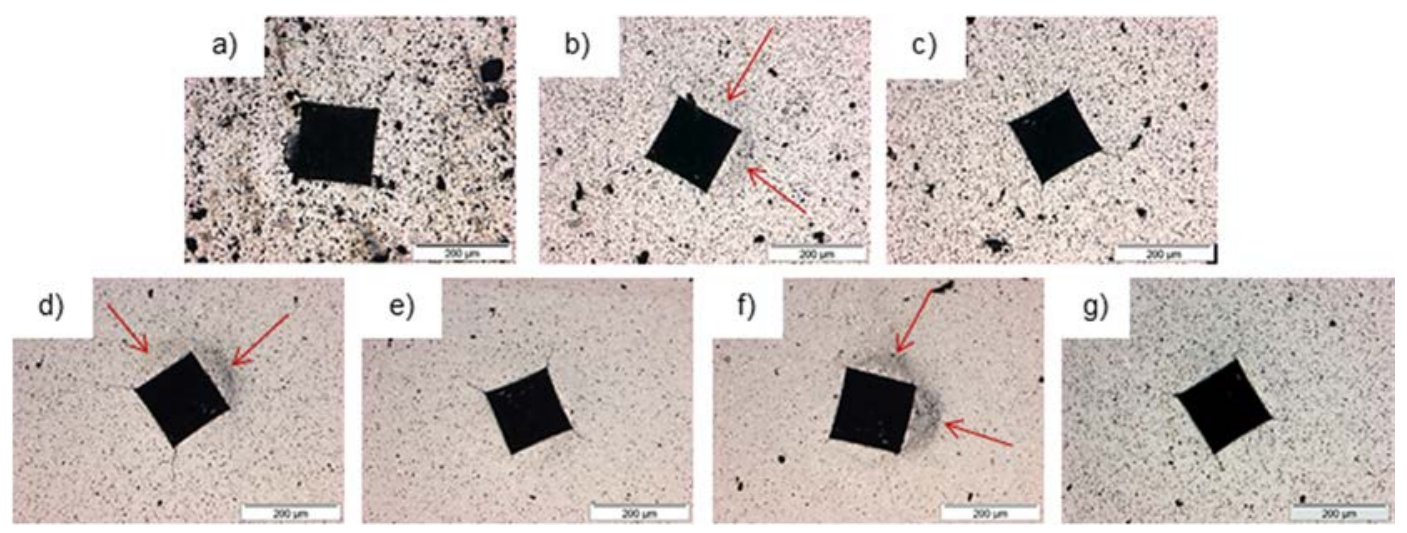

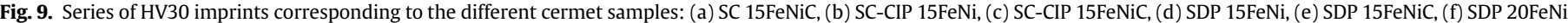
and $(\mathrm{g})$ SDP 20FeNiC

constant values were found for higher loads (i.e. from HV20 to HV30). Measured hardness values are consistent with those found in the literature related to the $\operatorname{Ti}(\mathrm{C}, \mathrm{N})$ based cermets of a similar composition (reinforcement phase $>80 \mathrm{wt} \%$ ) prepared by other techniques and/or using other binders. Some of them are as $\mathrm{TiC} / \mathrm{Fe}$ materials prepared by SPS [23], TiC/Ni prepared by uniaxial press ing with and without the addition of WC $[43,44]$, Ti(C,N)/Ni mixed with different carbides [1] or $(\mathrm{Ti}, \mathrm{W})(\mathrm{C}, \mathrm{N}) / \mathrm{Ni}$ prepared by high en ergy milling and adding WC [14].

In our analysis, based on the porosity values and the Vickers imprints in the micrographs of Fig. 9, a direct correlation between porosity and hardness can be appreciated. For a given composition (e.g. $15 \mathrm{FeNiC}$ ) bulk pieces processed by SDP show a higher sintered density (98.19\%) and higher hardness values (1301 HV30) than samples obtained by the other two processing methods, with SC (92.20\%, 925 HV30) and SC CIP (96.34\%, 1219 HV30). The same trend is observed for the $15 \mathrm{FeNi}$ samples (without $\mathrm{C}$ addition). The effect of the amount of metal in the composition can be appreciated between $15 \mathrm{FeNi}$ and $20 \mathrm{FeNi}$ samples processed by the SDP route. Although slightly less porosity was measured in the 20FeNi sam ples, a significant reduction in hardness was obtained compared to 15FeNi samples (e.g. 1120 vs. 1246 for HV30). In fact, a similar trend can be observed for samples containing $\mathrm{C}$, comparing $15 \mathrm{FeNiC}$ with 20FeNiC (e.g. 1301 vs. 1185 for HV30). In this regard, the effect of C addition and, as a consequence, the lowering of the liquidus tem perature of the metal phase and the improvement in wettability and impregnation of the ceramic phase, can be also inferred when comparing $15 \mathrm{FeNi}$ with $15 \mathrm{FeNiC}$ (i.e. 1246 vs. 1301 for HV30) or 20FeNi with $20 \mathrm{FeNiC}$ (i.e. 1120 vs. 1185 for HV30). Especially for high indentation loads, not only the hardness improves despite the slight reduction of density, but also the scatter in the hardness measurements decreases, manifesting the homogeneity of a better consolidated structure. Interestingly, "pile up" effects can be appreciated in the samples without C addition (see Fig. 9b, d, and f),
Ti(C,N) particles that can produce changes in the contiguity of the carbonitrides; (ii) higher sintering activation leading to higher diffusion rates of the metal matrix onto the $\mathrm{Ti}(\mathrm{C}, \mathrm{N})$ ceramic struc ture; (iii) changes in the stoichiometry of carbonitrides, or even (iv) diffusion or elimination of some Ni from the metal binder. In future work, the mechanical behavior of the different cermets in terms of strength and fracture resistance will be investigated. The high porosity content in the SC samples (affecting the hardness) may have detrimental effects on the strength of the cermet material. The additional pressing in the SC CIP samples may improve the me chanical behavior, due to the reduction of porosity, as reflected on the increase in hardness. Overall, the SDP route seems to be the most promising, as the density approaches $99 \%$ with very uniform microstructure and a relatively high hardness value.

\section{Conclusions}

The use of colloidal techniques combined with powder metal lurgy provides a new route for the processing of $\mathrm{Ti}(\mathrm{C}, \mathrm{N})$ based cermets that allows obtaining homogeneous microstructures, and near full dense materials with high fractions of ceramic phase (up to $85 \mathrm{vol} \%$ ) properly distributed in the metallic matrix. The pro posed route provides reliable results expanding the range of pos sibilities of processing bulk pieces from slurries of metal and non oxides particle mixtures.

Among the explored shaping methods, SDP cermets reach densities of $99.9 \%$. The spray dry of stable aqueous slurries with a high solid content yield solid and spherical composites granules, where the metal and the ceramic particles are homogeneously distributed. Those granules exhibit a high compressibility enabling their processing by conventional powder metallurgy (uniaxial pressing and vacuum sintering). The high dispersion of phases in the slurry replicates in the granules, leading to highly dense, ho mogeneous and fine microstructures after shaping and sintering. 
The sintering cycle was optimized to control the cermet composition, reducing the $\mathrm{N}_{2}$ lability, the final $\mathrm{O}_{2}$ content $(<0.2$ to wt.\%) and the Ni sublimation. In this sense, a sintering time as short as $120 \mathrm{~min}$ at $1450{ }^{\circ} \mathrm{C}$ in vacuum was adjusted, to provide equi librium between densification and composition matching the initially designed formulation.

Hardness values determined for $80-85$ wt\% Ti(C,N) materials processed by the proposed low energetic route are in the range of those reported in the literature for $\operatorname{Ti}(\mathrm{C}, \mathrm{N})$ based materials pre pared by SPS or high energetic milling using carbides and $100 \% \mathrm{Ni}$ matrix. Moreover, the addition of $\mathrm{C}$ to the cermet formulation promotes the microstructure hardening evidencing the key role of wettability and solubility of the well distributed phases in the microstructure features.

\section{Acknowledgements}

The authors acknowledge the financial support from the Span ish Government through the projects MAT2015 70780 C4 $1 \mathrm{P}$ and MAT2015 70780 C4 2 P, and the Regional Government of Madrid through the program MULTIMAT CHALLENGE, ref. S2013/MIT 2862. M.Dios acknowledges MINECO through the grant BES 2013 065760 .

\section{References}

[1] Y. Peng, H. Miao, Z. Peng, Development of TiCN-based cermets: mechanical properties and wear mechanism, Int. J. Refract. Met. Hard Mater. 39 (2013) 78 89, http://dx.doi.org/10.1016/j.ijrmhm.2012.07.001.

[2] J. Jung, S. Kang, Effect of nano-size powders on the microstructure of Ti(C,N)xWC-Ni cermets, Acta Mater. (2007), http://dx.doi.org/10.1111/j.15512916.2007.01654.x.

[3] L. Prakash, B. Gries, WC hardmetals with iron based binders, in: L. Sigl, P. Rodhammer, S. Wildner (Eds.), Proc 17th Int. Plansee Semin, vol. 2, 2009 Reutte.

[4] G. Gille, J. Bredthauer, B. Gries, B. Mende, W. Heinrich, Advanced and new grades of WC and binder powder their properties and application, Int. J. Refract. Met. Hard Mater. 18 (2000) 87 102, http://dx.doi.org/10.1016/S02634368(00)00002-0.

[5] W.D. Schubert, M. Fugger, B. Wittmann, R. Useldinger, Aspects of sintering of cemented carbides with Fe-based binders, Int. J. Refract. Met. Hard Mater. 49 (2015) 110 123, http://dx.doi.org/10.1016/j.ijrmhm.2014.07.028.

[6] P. Alvaredo, S.A. Tsipas, E. Gordo, Influence of carbon content on the sinterability of an FeCr matrix cermet reinforced with TiCN, Int. J. Refract. Met. Hard Mater. 36 (2013) 283 288, http://dx.doi.org/10.1016/j.ijrmhm.2012.10.007.

[7] Z. Guo, J. Xiong, M. Yang, J. Wang, L. Sun, Y. Wu, J. Chen, S. Xiong, Microstructure and properties of $\mathrm{Ti}(\mathrm{C}, \mathrm{N})$ Mo2C Fe cermets, Int. J. Refract. Met Hard Mater. 27 (2009) 781 783, http://dx.doi.org/10.1016/ j.ijrmhm.2009.01.003.

[8] H. Yu, Y. Liu, Y. Jin, J. Ye, Effect of secondary carbides addition on the microstructure and mechanical properties of $(\mathrm{Ti}, \mathrm{W}, \mathrm{Mo}, \mathrm{V})(\mathrm{C}, \mathrm{N})$-based cermets, Int. J. Refract. Met. Hard Mater. 29 (2011) 586 590, http://dx.doi.org/10.1016/ j.ijrmhm.2011.03.013.

[9] P. Alvaredo, J.J. Roa, E. Jiménez-Pique, L. Llanes, E. Gordo, Characterization of interfaces between TiCN and iron-base binders, Int. J. Refract. Met. Hard Mater. 63 (2017) 32 37, http://dx.doi.org/10.1016/j.ijrmhm.2016.08.010.

[10] P. Alvaredo, M.Dios, B.Ferrari, E.Gordo, Interface study for the design of alternative matrixes in cermets, EURO PM2015. Proceeding EURO PM2015. (n.d).

[11] S. Zhou, W. Zhao, W. Xiong, Microstructure and properties of the cermets based on Ti(C,N), Int. J. Refract. Met. Hard Mater. 27 (2009) 26 32, http:// dx.doi.org/10.1016/j.ijrmhm.2008.01.011.

[12] A. Rajabi, M.J. Ghazali, A.R. Daud, Chemical composition, microstructure and sintering temperature modifications on mechanical properties of TiC-based cermet a review, Mater. Des. 67 (2015) 95 106, http://dx.doi.org/ 10.1016/j.matdes.2014.10.081.

[13] O. Xu, X. Ai, J. Zhao, F. Gong, X. Tian, H. Zhang, Application of different dispersants in fabricating $\mathrm{Ti}(\mathrm{C}, \mathrm{N})$-based cermet tool materials, Key Eng. Mater. 693 (2016) 353 540, http://dx.doi.org/10.4028/www.scientific.net/ KEM.693.535.

[14] S. Park, S. Kang, Toughened ultra-fine (Ti,W)(CN) Ni cermets, Scr. Mater. 52 (2005) 129 133, http://dx.doi.org/10.1016/j.scriptamat.2004.09.017.

[15] I.W. Brown, W. Owers, Fabrication, microstructure and properties of Fe TiC ceramic metal composites, Curr. Appl. Phys. 4 (2004) 171 174, http:// dx.doi.org/10.1016/j.cap.2003.11.001.

[16] E. Chicardi, Y. Torres, M.J. Sayagués, V. Medri, C. Melandri, J.M. Córdoba, F.J. Gotor, Toughening of complete solid solution cermets by graphite addition, Chem. Eng. J. 267 (2015) 297 305, http://dx.doi.org/10.1016/ j.cej.2015.01.022

[17] E. Chicardi, F.J. Gotor, V. Medri, S. Guicciardi, S. Lascano, J.M. Córdoba, Hotpressing of $(\mathrm{Ti}, \mathrm{Mt})(\mathrm{C}, \mathrm{N})$ Co $\mathrm{Mo}_{2} \mathrm{C}(\mathrm{Mt} \mathrm{Ta}, \mathrm{Nb})$ powdered cermets synthesized by a mechanically induced self-sustaining reaction, Chem. Eng. J. 292 (2016) 51 61, http://dx.doi.org/10.1016/j.cej.2016.02.007.

[18] J.M. Córdoba, E. Chicardi, R. Poyato, F.J. Gotor, V. Medri, S. Guicciardi, C. Melandri, Spark plasma sintering of TixTa $1-x C 0.5$ N0.5-based cermets: effects of processing conditions on chemistry, microstructure and mechanical properties, Chem. Eng. J. 230 (2013) 558 566, http://dx.doi.org/10.1016/ j.cej.2013.06.104

[19] K. Das, T.K. Bandyopadhyay, S. Das, A review on the various synthesis routes of TiC reinforced ferrous based composites, J. Mater. Sci. 37 (2002) 38813892 , http://dx.doi.org/10.1023/A:1019699205003.

[20] E.A. Levashov, A.S. Mukasyan, A.S. Rogachev, D.V. Shtansky, Self-propagating high-temperature synthesis of advanced materials and coatings, Int. Mater. Rev. 62 (2017) 203 239, http://dx.doi.org/10.1080/09506608.2016.1243291.

[21] G. Liu, J. Li, K. Chen, Combustion synthesis of refractory and hard materials: a review, Int. J. Refract. Met. Hard Mater. 39 (2013) 90 102, http://dx.doi.org/ 10.1016/j.ijrmhm.2012.09.002.

[22] G. Liu, J. Li, K. Chen, One-step preparation of dense TiC1-xNx Ni3Ti cermet by combustion synthesis, Mater. Des. 87 (2015) 6 9, http://dx.doi.org/ 10.1016/j.matdes.2015.07.179.

[23] A. Jam, L. Nikzad, M. Razavi, TiC-based cermet prepared by high-energy ballmilling and reactive spark plasma sintering, Ceram. Int. 43 (2017) 24482455 , http://dx.doi.org/10.1016/j.ceramint.2016.11.039.

[24] Q. Xu, X. Ai, J. Zhao, W. Qin, Y. Wang, F. Gong, Comparison of Ti(C,N)-based cermets processed by hot-pressing sintering and conventional pressureless sintering, J. Alloys Compd. 619 (2015) 538 543, http://dx.doi.org/10.1016/ j.jallcom.2014.08.261.

[25] Y. Zheng, S. Wang, Y. Yan, N. Zhao, X. Chen, Microstructure evolution and phase transformation during spark plasma sintering of $\mathrm{Ti}(\mathrm{C}, \mathrm{N})$-based cermets, Int. J. Refract. Met. Hard Mater. 26 (2008) 306 311, http://dx.doi.org/10.1016/ j.ijrmhm.2007.08.001.

[26] A. Levy, A. Miriyev, A. Elliott, S.S. Babu, N. Frage, Additive manufacturing of complex-shaped graded TiC/steel composites, Mater. Des. 118 (2017) 198 203, http://dx.doi.org/10.1016/j.matdes.2017.01.024.

[27] N. Hernández, A.J. Sánchez-Herencia, R. Moreno, Forming of nickel compacts by a colloidal filtration route, Acta Mater. 53 (2005) 919 925, http:// dx.doi.org/10.1016/j.actamat.2004.10.038.

[28] S. Cabanas-Polo, R. Bermejo, B. Ferrari, A.J. Sanchez-Herencia, Ni NiO composites obtained by controlled oxidation of green compacts, Corros. Sci. 55 (2012) 172 179, http://dx.doi.org/10.1016/j.corsci.2011.10.016.

[29] J.A. Escribano, J.L. García, P. Alvaredo, B. Ferrari, E. Gordo, A.J. Sanchez-Herencia, FGM stainless steel-Ti(C,N) cermets through colloidal processing, Int. J. Refract. Met. Hard Mater. 49 (2015) 143 152, http://dx.doi.org/10.1016/ j.ijrmhm.2014.05.008.

[30] N. Hernández, R. Moreno, A.J. Sánchez-Herencia, J.L.G. Fierro, Surface behavior of nickel powders in aqueous suspensions, J. Phys. Chem. B 109 (2005) 4470 4474, http://dx.doi.org/10.1021/jp0448954.

[31] Z. Guo, J. Xiong, M. Yang, S. Xiong, J. Chen, Y. Wu, H. Fan, L. Sun, J. Wang, $\mathrm{H}$. Wang, Dispersion of nano-TiN powder in aqueous media, J. Alloys Compd. 493 (2010) 362 367, http://dx.doi.org/10.1016/j.jallcom.2009.12.103.

[32] R.G. Neves, B. Ferrari, A.J. Sanchez-Herencia, C. Pagnoux, E. Gordo, Role of stabilisers in the design of $\mathrm{Ti}$ aqueous suspensions for pressure slip casting, Powder Technol. 263 (2014) 8188 , http://dx.doi.org/10.1016/ j.powtec.2014.04.093.

[33] R.G. Neves, B. Ferrari, A.J. Sanchez-Herencia, E. Gordo, Colloidal approach for the design of Ti powders sinterable at low temperature, 2013. http://dx.doi.o rg/10.1016/j.matlet.2013.05.015.

[34] J.A. Escribano, B. Ferrari, P. Alvaredo, E. Gordo, A.J. Sánchez-Herencia, Colloidal processing of Fe-based metalceramic composites with high content of ceramic reinforcement, in: Bol Soc Esp Cerámica Vidr, vol. 52, 2013.

[35] L. Dusoulier, R. Cloots, B. Vertruyen, R. Moreno, O. Burgos-Montes, B. Ferrari, $\mathrm{YBa}_{2} \mathrm{Cu}_{3} \mathrm{O}_{7} \times$ dispersion in iodine acetone for electrophoretic deposition: surface charging mechanism in a halogenated organic media, J. Eur. Ceram. Soc. $\quad 31 \quad(2011) \quad 1075$ 1086, http://dx.doi.org/10.1016/ j.jeurceramsoc.2011.01.008.

[36] I. Gonzalo-Juan, B. Ferrari, M.T. Colomer, A.J. Sánchez-Herencia, Colloidal processing and sintering of porous percolative Ni-YSZ layers, J. Memb. Sci. 352 (2010) 55 62, http://dx.doi.org/10.1016/j.memsci.2010.01.060.

[37] L. Chen, $\mathrm{W}$. Lengauer, $\mathrm{K}$. Dreyer, Advances in modern nitrogen-containing hardmetals and cermets, Int. J. Refract. Met. Hard Mater. 18 (2000) 153 161, http://dx.doi.org/10.1016/S0263-4368(00)00016-0.

[39] S. Wawrzik, P. Zhou, C. Buchegger, W. Lengauer, Metallurgy and thermochemistry of cermet/hardmetal laminates, Int. J. Refract. Met. Hard Mater. 50 (2015) 282 289, http://dx.doi.org/10.1016/j.ijrmhm.2015.02.007.

[40] V. Tracey, Nickel in hardmetals, Int. J. Refract. Met. Hard Mater. 11 (1992) 137 149, http://dx.doi.org/10.1016/0263-4368(92)90056-8.

[41] J. Gong, J. Wu, Z. Guan, Examination of the indentation size effect in low-load vickers hardness testing of ceramics, J. Eur. Ceram. Soc. 19 (1999) 26252631 , http://dx.doi.org/10.1016/S0955-2219(99)00043-6.

[42] J.B. Quinn, G.D. Quinn, Indentation brittleness of ceramics: a fresh approach, J. Mater. Sci. 32 (1997) 4331 4346, http://dx.doi.org/10.1023/A: 1018671823059. 
[43] E.T. Jeon, J. Joardar, S. Kang, Microstructure and tribo-mechanical properties of ultrafine Ti(CN) cermets, Int. J. Refract. Met. Hard Mater. 20 (2002) 207211 http://dx.doi.org/10.1016/S0263-4368(02)00004-5.

[44] S. Acharya, M. Debata, T.S. Acharya, P.P. Acharya, S.K. Singh, Influence of nickel boride addition on sintering behaviour and mechanical properties of TiC $\mathrm{Ni}$ based cermets, J. Alloys Compd. 685 (2016) 905 912, http://dx.doi.org/ 10.1016/j.jallcom.2016.06.122.
[45] A.E. Giannakopoulos, P.-L. Larsson, R. Vestergaard, Analysis of vickers indentation, Int. J. Solids Struct. 31 (1994) 2679 2708, http://dx.doi.org/10.1016 0020-7683(94)90225-9.

[46] M. Chen, Q. Zhuang, N. Lin, Y. He, Improvement in microstructure and mechanical properties of $\mathrm{Ti}(\mathrm{C}, \mathrm{N})-\mathrm{Fe}$ cermets with the carbon additions, J. Alloys Compd. 701 (2017) 408 415, http://dx.doi.org/10.1016/j.jallcom.2017.01.119. 